\title{
EFEITO DO NÚMERO DE LIBERAÇÕES DE Trichogramma galloi (ZUCCHI, 1988) NO PARASITISMO DE OVOS DE Diatraea saccharalis (FABR., 1794) ${ }^{1}$
}

\author{
P.S.M. BOTELHO ${ }^{2}$; J.R.P. PARRA ${ }^{3,5}$; E.A. MAGRINI ${ }^{3,6}$; M.L. HADDAD ${ }^{3,5}$; L.C.L. RESENDE ${ }^{4}$ \\ ${ }^{2}$ CCA/UFSCar, C.P. 153, CEP: $13600-970-$ Araras, SP, \\ ${ }^{3}$ Departamento de Entomologia-ESALQ/USP, C.P. 9, CEP: 13418-900-Piracicaba,SP \\ 'Usina São João de Araras, C.P. 13, CEP: 13600-970 - Araras,SP \\ ${ }^{5}$ Bolsista do $C N P q$ \\ ${ }^{\circ}$ Bolsista da CAPES
}

RESUMO: O trabalho teve por objetivo estudar o efeito do número de liberações semanais de Trichogramma galloi Zucchi, 1988, em áreas de cana-de-açúcar sucessivamente infestadas com ovos de Diatraea saccharalis (Fabr., 1794). Foram conduzidos experimentos com a variedade $R B$ 72454 , com seis e nove meses de idade, em duas regiōes distintas, espaçamento de $1,40 \mathrm{~m}$, sendo por região, demarcadas quatro áreas de um hectare, delimitando-se no centro delas, uma parcela com $400 \mathrm{~m}^{2}$. Cada parcela foi, por três semanas consecutivas, infestada com 25 casais de D. saccharalis, liberando-se $T$, galloi da seguinte forma (tratamentos): 1. sem liberação (testemunha); 2 . uma liberação logo após a primeira infestação artificial; 3. duas liberações, uma logo após a primeira infestação artificial e outra apos a segunda infestação com intervalo de sete dias; 4. três liberações, cada uma logo após a infestação artificial a intervalos semanais. Pôde-se concluir, para ambos os experimentos, que para se manter elevado o parasitismo de ovos, por $T$, galloi, no período crítico de oviposição de $D$. saccharalis, são necessárias liberações sucessivas do parasitóide.

Descritores: controle biológico, broca-da-cana-de-açúcar, Diatraea saccharalis, Trichogramma galloi

\section{EFFECT OF THE NUMBER OF Trichogramma galloi (ZUCCH, 1988) RELRASES ON EGG PARASITIZATION OF Diatraea saccharalis (FABR., 1794)}

\begin{abstract}
ARSTRACT: This work was carried out to study the effect of weekly releases of Trichogramma galloi Zucchi, 1988 on egg parasitism of the sugarcane borer, Diatraea saccharalis (Fabr., 1794). The research was conducted in two distinct regions of the State of São Paulo, Brazil, using the sugarcane variety RB 72454, six and nine months old, cultivated in a spacing of $1.40 \mathrm{~m}$. The experimental plots were artificially infested with sugarcane borer eggs on a weekly basis during 3 weeks, as following: a - Control (no releases); b - one $T$. galloi release after the first egg infestation; c - two $T$. galloi releases: one after the first egg infestation and the other following the second egg infestation; $d$ - three weekly releases of $T$. galloi. The results showed that weekly releases are necessary to maintain high levels of $T$. galloi parasitization during the peak period of sugarcane borer eggs.

Key Words: biological control, sugarcane borer, Diatraea saccharalis, Trichogramma galloi

\section{INTRODUÇÃO}

O enfoque conservacionista que ganha corpo na atualidade, com a crescente preocupação em analisar os impactos ambientais causados pela atividade humana nas mais diversas situações, abre grandes perspectivas para a utilização do controle

biológico no manejo de insetos em diversas culturas, e, em especial, em cana-de-açúcar. Segundo PARRA (1992), o controle biológico pode ser enfocado sob dois aspectos: o controle biológico natural, que ocorre sem a interferência do homem (naturalmente) e o controle biológico aplicado que envolve a intervenção humana.
\end{abstract}

1 Pesquisa parcialmente financiada pelo CNPq/RHAE 
- controle biológico, através de liberações inundativas de parasitóides de ovos como Trichogramma (controle biológico aplicado), apresenta a vantagem de poder reduzir a população da praga antes que algum dano seja causado à cultura. Entretanto, tendo em vista ser a cana-deaçúcar uma cultura de ciclo longo, permitindo o desenvolvimento de várias gerações de Diatraea saccharalis (Fabr., 1794) (BOTELHO, 1985), considera-se necessária a realização de liberações sucessivas, por períodos variáveis (METCALFE \& BRENIĖRE, 1969). No Peru, as liberações para o controle de $D$. saccharalis são recomendadas para os primeiros meses da cultura, quando a infestação de ovos da praga é elevada e o parasitismo natural É insatisfatório (CUEVA, 1980). No Brasil, LOPES (1988) recomendou a liberação de Trichogramma galloi Zucchi, 1988, para o controle de $D$. saccharalis, quando se observarem os primeiros ovos da praga na cultura.

Embora tenham sido recomendadas várias liberações de Trichogramma em cana-de-açúcar, MING-FANG (1988), na China, testou uma única liberação do parasitóide, no início da primavera, contra seis a sete liberações no decorrer da cultura. Os resultados obtidos mostraram que não houve diferenças na eficiência de controle nas duas situações estudadas.

Este trabalho teve por objetivo estudar o efeito do número de liberações de $T$. galloi no parasitismo de ovos de $D$. saccharalis.

\section{MATERIAL E MÉTODOS}

Foram conduzidos dois experimentos, um no Centro de Ciências Agrárias da Universidade Federal de São Carlos - CCA/UFSCar e outro na Usina São João, ambos no município de Araras, Estado de São Paulo. Utilizou-se a variedade RB 72454, plantio de maio e novembro de 1991, respectivamente, no espaçamento de $1,40 \mathrm{~m}$, com seis (CCA/UFSCar) e nove (Usina São João) meses de idade. Foram demarcadas quatro áreas de um hectare cada, sendo que em cada uma delas foi delimitada uma parcela central de $400 \mathrm{~m}^{2}(20 \times 20$ metros).

Cada parcela de $400 \mathrm{~m}^{2}$ foi, por três semanas consecutivas, infestada com 25 casais de $D$. saccharalis. Os casais provenientes de criação de laboratório, segundo técnica de MACEDO et al., (1983) foram distribuídos ao acaso na parcela, empregando a metodologia de LOPES et al. (1989).
Adultos de Trichogramma galloi Zucchi, 1988, linhagem número 13 do Departamento de Entomologia da ESALQ/USP, criados sobre ovos de Anagasta kuehniella (Zeller, 1879), provenientes da produção do laboratório, segundo técnica descrita por PARRA et al. (1989), foram liberados conforme LOPES (1988) na proporção de $600 \mathrm{mil}$ parasitoides por hectare (CCA/UFSCar) ou 200 $\mathrm{mil} / \mathrm{ha}$ (Usina São João). Nos quatro tratamentos foram realizadas três infestações sucessivas com 25 casais de $D$. saccharalis cada, espaçadas uma semana entre si. Os tratamentos foram os seguintes:

\section{Sem liberação de $T$. galloi (testemunha).}

2. Uma liberação de $T$. galloi logo após a primeira infestação artificial com ovos de $D$. saccharalis.

3. Duas liberaçôes, uma logo após a prımeira infestação artificial e outra após a scgunda infestação, com intervalo de sete dias.

4. Três liberações, cada uma logo após a infestação artificial, a intervalos semanais.

Dois dias após a liberação, as folhas de cana-de-açúcar, previamente marcadas nos diferentes tratamentos, foram retiradas do campo e a secção de folha contendo os ovos de $D$. saccharalis, contada e acondicionada em placa de Petri, em câmara BOD regulada a $25 \pm 1^{\circ} \mathrm{C}$ e 14 horas de fotofase. Quatro dias após, as folhas foram examinadas ao microscópio estereoscópico, contando-se o número de ovos parasitados e não parasitados por folha. Os dados obtidos foram transformados em porcentagem e analisados através do delineamento experimental "split-plot". As médias foram comparadas pelo teste de Tukey, ao nível de $5 \%$ de probabilidade.

\section{RESULTADOS E DISCUSSÃo}

\section{Experimento no CCA/UFSCar}

A despeito de ter havido número diferente de liberações entre tratamentos, pôde-se constatar que hoùve tendência de acréscimo de parásitismo nas áreas liberadas. Assim, a porcentagem média de ovos parasitados por Trichogramma galloi Zucchi, 1988, nas três semanas, nas parcelas onde houve liberaçōes, foi de 27,$13 ; 58,83$ e $92,08 \%$ (TABELA 1). 
TABELA 1. Porcentagem de ovos de Diatraea saccharalis parasitados por Trichogramma galloi, por semana. CCA/UFSCar, Araras-SP.

\begin{tabular}{|c|c|c|c|c|}
\hline \multirow{2}{*}{$\begin{array}{l}N^{\circ} \text { de } \\
\text { liberações }\end{array}$} & \multicolumn{3}{|c|}{ Semanas } & \multirow{2}{*}{ Média } \\
\hline & 1 & 2 & 3 & \\
\hline
\end{tabular}

\begin{tabular}{cccccc}
\hline 0 & $1,23 \mathrm{c}$ & $51,56 \mathrm{~b}$ & $66,02 \mathrm{ab}$ & $31,93 \mathrm{c}$ \\
1 & $15,37 \mathrm{~b}$ & $21,56 \mathrm{c}$ & $49,86 \mathrm{bc}$ & $27,13 \mathrm{c}$ \\
2 & $63,49 \mathrm{a}$ & $99,93 \mathrm{a}$ & $25,46 \mathrm{c}$ & $58,83 \mathrm{~b}$ \\
3 & $77,74 \mathrm{a}$ & $99,91 \mathrm{a}$ & $99,48 \mathrm{a}$ & $92,08 \mathrm{a}$
\end{tabular}

Médias seguidas de mesma letra na coluna não diferem entre si pelo teste de Tukey, ao nível de $5 \%$ de probabilidade.

$\mathrm{Na}$ primeira semana, foram obtidos parasitismos variáveis de $15,37 \%$ e $77,74 \%$ nas áreas de liberação, enquanto que na testemunha registrou-se 1,23\% de ovos parasitados (TABELA 1). Essa constatação de um pequeno parasitismo na testemunha no início das liberações coincide com os resultados de CUEVA (1979), AYQUIPA et al. (1980) e LOPES (1988) que verificaram um reduzido e esporádico parasitismo natural até o $6^{\circ}$ e $7^{\circ}$ meses após o plantio, período que coincide com a época de realização desse experimento $\left(6^{\circ}\right.$ mês). Os parasitismos obtidos na segunda semana, quando somente foram realizadas liberações nos tratamentos três e quatro, foram muito altos $(99,93 \%$ e $99,91 \%$, respectivamente), diferindo significativamente dos demais. Entretanto, pôde-se constatar elevado parasitismo também na testemunha, se comparado à primeira semana de liberação. Esse aumento se deve, provavelmente, à população migrante no campo, proveniente da segunda liberação e ao aumento da população de ovos na área experimental em razão de infestação artificial, atraindo insetos de outras áreas pela maior presença de cairomônios (LEWIS et al., 1975). Esta hipótese é respaldada no trabalho de SÁ (1991) que observou um maior parasitismo de Trichogramma pretiosum Riley, 1879 quando havia maior número de ovos de Helicoverpa zea (Boddie, 1880), pois a presença do hospedeiro interceptava e retinha uma maior população de parasitóides na área. Por outro lado, nessa época, não havia tempo suficiente para ocorrer uma geração do parasitóide no campo a partir dos insetos liberados na primeira semana, pois segundo LOPES (1988), baseado em dados de laboratório, o período efetivo de parasitismo por $T$. galloi $\in$ de três a quatro dias e ocorre uma geração do parasitoide, em média, a cada 15 dias.

Os resultados da terceira semana quando apenas o tratamento quatro recebeu liberação, confirmaram um alto parasitismo nesse local $(99,48 \%)$ e na testemunha $(66,02 \%)$ e valores menores nos dois outros tratamentos (TABELA 1). As mesmas razões usadas para interpretar o alto parasitismo na segunda semana do experimento, podem ser aqui consideradas, acrescidas do fato de que na terceira semana, teoricamente, já havia tempo suficiente para o ciclo completo da primeira geração de campo, desenvolvida sobre ovos parasitados remanescentes da primeira semana de liberação. Esta hipótese entretanto, não explica o menor parasitismo observado nos tratamentos dois e três.

Em termos médios ficou evidente que foi possível manter alto nível de parasitismo com liberações sucessivas (TABELA 1), recomendadas por LOPES (1988) e por De BACH \& BARTLETT (1964). Estes últimos autores afirmaram inclusive, que para ocorrer uma atuação uniforme do parasitóide durante todo o período crítico de oviposição da praga, as liberações devem ser realizadas a intervalos de, no máximo, sete dias.

\section{Experimento na Usina São João}

Os níveis de parasitismo obtidos na primeira semana foram baixos (TABELA 2), possivelmente em razão da temperatura nos dias de liberação de $T$. galloi com mínimas de $9,4^{\circ} \mathrm{C}$. A temperatura média no dia de liberação $\left(14,6^{\circ} \mathrm{C}\right)$ esteve muito próxima do limite término inferior de desenvolvimento de $T$. galloi que, segundo SALES Jr. \& PARRA (1992) é de $12,6^{\circ} \mathrm{C}$, explicando assim seu baixo desempenho nessa semana. Já na segunda semana, os parasitismos foram mais elevados variando entre 35,86 a $53,97 \%$ (TABELA 2), diferindo da testemunha, onde não houve liberação do parasitóide. Entretanto, foi observado um parasitismo de $49,85 \%$ no tratamento 2 , onde também não foi liberado $T$. galloi, podendo este alto valor ser atribuído aos parasitóides que permaneceram no campo na semana posterior à sua liberação e que teriam tido maior longevidade em razão da queda na temperatura na semana anterior. Esta hipótese baseia-se nas observações de SALES Jr. (1992) que, em condições de laboratório, 
encontrou longevidades que variaram de 9,59 a 15,17 dias, dependendo da umidade relativa, na temperatura de $20^{\circ} \mathrm{C}$, próxima à máxima obtida no dia da primeira liberação $\left(19,9^{\circ} \mathrm{C}\right) . \mathrm{Na}$ terceira semana do experimento obteve-se o parasitismo de $36,42 \%$ na parcela onde houve liberação do $T$. galloi diferindo significativamente dos demais tratamentos (TABELA 2).

TABELA 2. Porcentagem de ovos de Diatraea saccharalis parasitados por Trichogramma galloi por semana. Usina São João, Araras - SP.

\begin{tabular}{cccc}
\hline \multirow{2}{*}{$\begin{array}{c}N^{0} \text { de } \\
\text { liberações }\end{array}$} & \multicolumn{4}{c}{ Semanas } \\
\cline { 2 - 4 } & \multicolumn{3}{c}{$\%$} \\
\multicolumn{3}{c}{ Parasitismo } \\
\hline 0 & $0,00 \mathrm{~b}$ & $0,00 \mathrm{~b}$ & $0,00 \mathrm{~b}$ \\
1 & $3,13 \mathrm{ab}$ & $49,85 \mathrm{a}$ & $8,15 \mathrm{~b}$ \\
2 & $13,71 \mathrm{a}$ & $35,86 \mathrm{a}$ & $6,87 \mathrm{~b}$ \\
3 & $1,29 \mathrm{ab}$ & $53,97 \mathrm{a}$ & $36,42 \mathrm{a}$ \\
\hline
\end{tabular}

Médias seguidas por mesma letra na coluna não diferem entre si, pelo teste de Tukey, ao nível de $5 \%$ de probabilidade.
Nesse experimento, ficou mais uma vez evidenciado que somente com liberações semanais, em áreas que são sucessivamente infestadas com ovos é possível manterem-se níveis elevados de parasitismo, à semelhança do que já havia sido constatado no experimento no CCA/UFSCar. Ficou também evidente, a despeito das quantidades de parasitóides liberados, variáveis de 200 a $600 \mathrm{mil} /$ ha e da idade do canavial (entre 6 e 9 meses), que ocorreram grandes diferenças nas porcentagens de parasitismo nos dois experimentos (Figura 1). Estas variações ocorreram, provavelmente, em função de características edáficas, climáticas e fenológicas locais (LOPES, 1988 e BOTELHO et al., 1993).

\section{REFERÊNCIAS BIBLIOGRÁFICAS}

AYQUIPA, A.G.; VALDERRAM, T.A.; SIRLOPÚ, J.R. The Trichogramma sp parasitism on eggs of Diatraea saccharalis (Fabr.), in Casa Grande. Entomology Newsletter, Araras, v.9, p.4, 1980.

BOTELHO, P.S.M. Tabela de vida ecológica e simulação da fase larval da Diatraea saccharalis (Fabr., 1794) (Lep., Pyralidae). Piracicaba, 1985. 110p. Tese (Doutorado) - Escola Superior de Agricultura "Luiz de Queiroz", Universidade de Sāo Paulo.

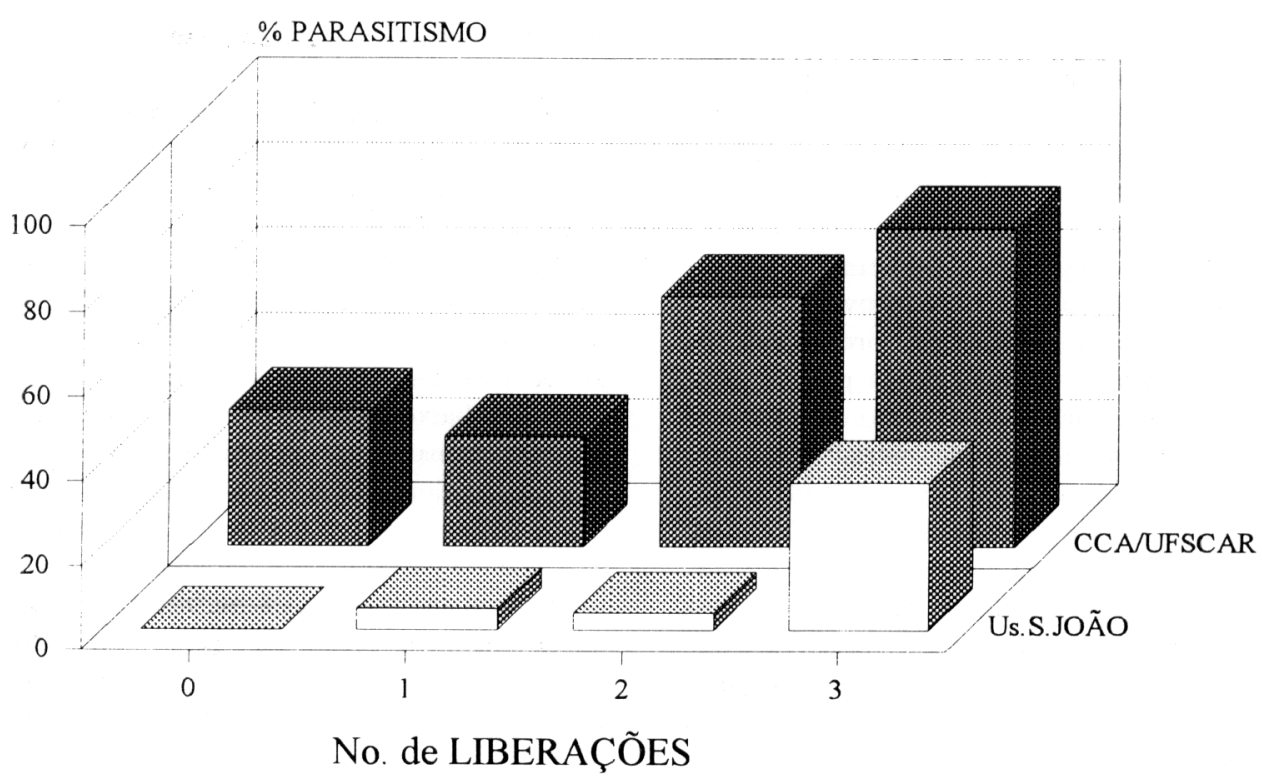

Figura 1. Porcentagem de ovos de D. saccharalis, parasitados por $T$. galloi com diferentes números de li-beraçöes em 2 locais de Araras, SP. 
BOTELHO, P.S.M.; PARRA, J.R.P.; MAGRINI, E.A.; HADDAD, M.L.; RESENDE, L.C.L. Parasitismo de ovos de Diatraea saccharalis por Trichogramma galloi em diferentes variedades de cana-de-açúcar. 1993. Anais da Sociedade Entomologica do Brasil, Jaboticabal, 1993. (no prelo).

CUEVA, C.M. Estudio preliminar de las poblaciones de huevos de Diatraea saccharalis (F.) y sus parasitos naturales en la caña de azúcar. Revista Peruana de Entomologia, Lima, v.22, n.1, p.25-28, 1979.

CUEVA, C.M. Diatraea saccharalis (Fabr.) y sus factors bioticos de mortalidad natural durante el periodo vegetativo de la caña de azúcar. Revista Peruana de Entomologia, Lima, v.23, n.1, p.77-81, 1980.

DE BACH, P.; BARTLETT, B.R. Methods of colonization, recovery and evaluation. In: DE BACH, P., ed. Biological control of insect pests and weeds. New York: Reinhold, 1964. p.402-428.

LEWIS, W.J.; JONES, R.L.; NORDLUND, D.A.; GROSS JR., H.R. Kairomones and their use for management of entomophagous insects. II, Mechanisms causing increase in rate of parasitization by Trichogramma spp. Joumal of Chemical Ecology, New York, v.1, n.3, p.349-360, 1975.

LOPES, J.R.S. Estudos bioetológicos de Trichogramma galloi Zucchi 1988 (Hym., Trichogrammatidae) para o controle de Diatraea saccharalis (Fabr., 1794) (Lep., Pyralidae). Piracicaba, 1988. 141p. Dissertação (Mestrado) - Escola Superior de Agricultura "Luiz de Queiroz", Universidade de São Paulo.

LOPES, J.R.S.; PARRA, J.R.P.; JUSTI JÚNIOR. J.; OLIVEIRA, N.H. Metodologia para infestação artificial de ovos de Diatraea saccharalis (Fabr., 1794) em cana-de-açúcar visando estudos com Trichogramma spp. Anais da Escola Superior de Agricultura "Luiz de Queiroz", Piracicaba, v.46, pte.2, p.375-390, 1989.

MACEDO, N.; BOTELHO, P.S.M.; DEGASPARI, N.; ALMEIDA, L.C.; ARAÚJO, J.R.; MAGRINI, E.A. Controle biológico da broca da cana-de-açúcar; manual de instrução. Piracicaba: IAA/PLANALSUCAR, 1983. 22p.
METCALFE, J.R.; BRENIÈRE, J. Egg parasites (Trichogramma spp.) for control of sugar cane moth borers. In: WILLIANS, J.R.; METCALFE, J.R.; MUNDOMERY, R.W.; MATHES, R., eds. Pests of sugar cane. New York: Elsevier, 1969. p.81-115.

MING-FANG, G. New method of Trichogramma utilization. In: INTERNATIONAL SYMPOSIUM ON TRICHOGRAMMA AND OTHER EGG PARASTTES, 2, Guangzhou, 1986. Paris: INRA, 1988. Les Colloques de L'INRA, Paris, n.43, p.469-476. 1988.

PARRA, J.R.P. Situação atual e perspectiva do controle biológico, através de liberações inundativas, no Brasil. Pesquisa Agropecuária Brasileira, Brasília, v.27, p.271-279, abr. 1992.

PARRA, J.R.P.; LOPES, J.R.S.; SERRA, H.J.P.; SALES JR., O. Metodologia de criação de Anagasta kuehniella (Zeller, 1879) para a produção massal de Trichogramma spp. Anais da Sociedade Entomológica do Brasil, Jaboticabal, v.18, n.2, p.403-415, 1989.

SÁ, L.A.N. de. Bioecologia de Trichogramma pretiosum Riley, 1879, visando avaliar o seu potencial para controle de Spodoptera frugiperda (J.E. Smith, 1797) e Helicoverpa zea (Boddie, 1850) em milho. Piracicaba, 1991. 107p. Tese (Doutorado) - Escola Superior de Agricultura "Luiz de Queiroz", Universidade de São Paulo.

SALES JÚNIOR, O. Bioecologia de Trichogramma galloi Zucchi, 1988 no hospedeiro natural Diatraea saccharalts (Fabricius, 1794) e em hospedeiros alternativos. Piracicaba, 1992.97p. Tese (Doutorado) - Escola Superior de Agricultura "Luiz de Queiroz", Universidade de São Paulo.

SALES JÚNIOR, O.; PARRA, J.R.P. Exigências térmicas de Trichogramma galloi Zucchi, no hospedeiro natural Diatraea saccharalis (Fabr.). In: SIMPÓSIO DE CONTROLE BIOLÓGICO, 3, Águas de Lindóia, 1992. Anais. Jaguariúna: EMBRAPA/CNPDA, 1992. p.208.

Entregue para publicaçâo em 03.05.94

Aceito para publicaçāo em 01.08 .94 